\title{
Studies on the Biosynthesis of $\gamma$-Decalactone in Sporobolomyces odorus
}

\begin{abstract}
Wolfgang Albrecht and Roland Tressl
Technische Universität Berlin, Institut für Biotechnologie, Fachgebiet Chemisch-technische Analyse, Seestraße 13, D-1000 Berlin 65, Bundesrepublik Deutschland

Z. Naturforsch. 45c, 207-216 (1990); received November 17, 1989/January 18, 1990

Dedicated to Professor Friedrich Drawert on the occasion of his 65th birthday

Incubation of racemic ethyl $\left[2,2-{ }^{2} \mathrm{H}_{2}\right]-(E)-3,4$-epoxydecanoate and the corresponding acid with intact cells of Sporobolomyces odorus led to the formation of deuterium labeled $\gamma$-decalactone. The detection of labeled 2-decen-4-olide and 4-oxodecanoic acid made it possible to propose the biogenetic sequence leading to $\gamma$-decalactone. The determination of the enantiomeric ratio of the lactone revealed an unspecific metabolism of the precursor. In contrast to the $(E)$-isomer, after administration of ethyl $\left[5,6-{ }^{2} \mathrm{H}_{2}\right]-(Z)-3,4$-epoxydecanoate no transformation could be detected. These results indicate that $(E)-3,4$-epoxydecanoic acid, formed from (E)-3-decenoyl-CoA, an intermediate of the $\beta$-oxidation of linoleic acid, is the genuine precursor in the biosynthesis of $\gamma$-decalactone.
\end{abstract}

\section{Introduction}

Although aliphatic $\gamma$ - and $\delta$-lactones are important compounds, e.g. as flavor constituents in foodstuffs and as attractants in pheromone research [1-3], their biogenetic formation still awaits elucidation. The identification of presumable precursor compounds as trace constituents in the spectrum of plant volatiles [4] and the detection of various enzymatic activities by incubation experiments with fruit tissue made it possible to propose some biogenetic pathways [5, 6].

Glycerol bound 4- and 5-keto acids, identified as trace constituents in milk fat [7,8], have been discussed as potential precursor compounds of $\gamma$ and $\delta$-lactones in fermented milk products. The reduction of 4- and 5-keto acids by microorganisms are well known transformations [9], but the formation of these keto acyl glycerols in milk fat remained unclear.

Walker and Dimick postulated a $\delta$-oxidation of saturated fatty acyl CoA-esters after acetate derived de novo synthesis of the corresponding acids $[10,11]$. The first intermediate of this pathway, 4-enoyl CoA, might be enzymatically hydrated to the 4- or 5-hydroxy derivative, the immediate biogenetic precursor of the lactones.

When $\left[1-{ }^{14} \mathrm{C}\right]$ decanoic acid was administered to cells of the lactone producing red yeast $S$. odorus, $\gamma$-decalactone contained $84 \%$ of the total radioac-

Reprint requests to R. Tressl.

Verlag der Zeitschrift für Naturforschung, D-7400 Tübingen 0341-0382/90/0300-0207 \$01.30/0 tivity in the extracts of volatiles [12]. But, corresponding to the results of Dimick and Walker, no intermediates were detected, which made it possible to confirm the mechanistic pathway.

The increase in concentration of $\gamma$-dodecalactone and ( $Z$ )-6-dodecen-4-olide in the milk of ruminants after application of a diet with a high degree of oleic and linoleic acid [13] indicated that these lactones might derive from the degradation of long chain fatty acids.

Detailed physiological studies on S. odorus revealed that the degradation of previously biosynthesized fatty acids corresponds with an enhanced accumulation of $\gamma$-nona-, $\gamma$-decalactone and $(Z)$ 6-dodecen-4-olide [14].

$(Z, Z)$-3,6-dodecadienoyl-CoA, $(Z)$-4-decenoylCoA and $(E, Z)$-2,4-decadienoyl-CoA are intermediates of the $\beta$-oxidation of linoleic acid $[15,16]$. However, no hydration of these possible precursors leading to the corresponding 4-hydroxyacyl intermediates could be demonstrated in previous investigations $[17,18]$.

Based on these results and on the fact that cytochrome P-450 dependent monooxygenases catalyze the hydroxylation of different compounds, e.g. fatty acids, hydrocarbons and steroids [19], we assumed that a comparable enzymatic system is responsible for the formation of aliphatic lactones. In incubation experiments with cells of $S$. odorus using various deuterated fatty acids, such as $(Z)$-4-decenoate, $(E)$-3-decenoate and decanoate, no transformation neither into $\gamma$ - nor into $\delta$-decalactone could be detected [20]. 
For the purpose to trace the metabolic routes leading to $\gamma$-decalactone the capacity of submerged strawberry tissue to transform racemic $\left[2,2-{ }^{2} \mathrm{H}_{2}\right]-(E)-3,4$-epoxydecanoic acid into the lactone could be demonstrated [14]. The optical purity of the product, however, did not correspond to the naturally formed optical pure $(R)-(+)-$ $\gamma$-decalactone.

In this paper the biogenetic pathway of $\gamma$-decalactone is proposed based on the results obtained after GC-MS identification of metabolites and chiral analysis of the lactone formed after incubation of deuterium labeled (E)-3,4-epoxydecanoic acid.

\section{Materials and Methods}

\section{Chemicals}

(E)-3-decenoic acid was obtained from Ferak (Berlin, F.R.G.), (E)-2-heptenal, ethyl acrylate, and triphenylphosphine were purchased from Aldrich (Steinheim, F.R.G.), $\mathrm{D}_{2} \mathrm{O}$ and $\mathrm{NaOD}(30 \%$ in $\mathrm{D}_{2} \mathrm{O}$ ) were from Roth (Karlsruhe, F.R.G.); pig liver esterase (EC 3.1.1.1.) $260 \mathrm{U} / \mathrm{mg}$ protein from Sigma (Deisenhofen, F.R.G.); $(R)-(+)-1$-phenylethylisocyanate (PEIC), N,N-4-dimethylaminopyridine and $m$-chloroperbenzoic acid (mCPBA) from Fluka (Neu-Ulm, F.R.G.) and 2-decen4-olide was a gift from Haarmann \& Reimer (Holzminden, F.R.G.).

\section{Syntheses}

Ethyl $\left[2,2-{ }^{2} \mathrm{H}_{2}\right]-(E)-3,4$-epoxydecanoate

$1 \mathrm{~g}(E)$-3-decenoic acid, $200 \mu \mathrm{l} \mathrm{NaOD}$ and $3 \mathrm{ml}$ $\mathrm{D}_{2} \mathrm{O}$ were heated in a gastight reaction vessel for $24 \mathrm{~h}$ at $170{ }^{\circ} \mathrm{C}$. After acidification and extraction, the product was esterified with ethanol/acetylchloride (9:1).

EI-MS (Ethyl $\left[2,2-{ }^{2} \mathrm{H}_{2}\right]-(E)-3$-decenoate): $\mathrm{m} / \mathrm{z}$ $200\left(\mathrm{M}^{+}\right.$, rel. int. $\left.0.8 \%\right), 56(100), 43(84), 41(76)$, 57 (69), 55 (67), 69 (67), 110 (63), 90 (60), 70 (58), 71 (53); Kovats-Index (IK) DB Wax 60 W: 1680.

$950 \mathrm{mg}$ mCPBA ( $=5.5 \mathrm{mmol})$, dissolved in $2.5 \mathrm{ml}$ diethylether were added to $0.93 \mathrm{~g}$ ester $(=5 \mathrm{mmol})$, dissolved in $5 \mathrm{ml}$ ether at $0{ }^{\circ} \mathrm{C}$. After $48 \mathrm{~h}$, the solvent was evaporated and the product was cleaned up by silica gel liquid solid chromatography (LSC) (glass column, $80 \times 1.5 \mathrm{~cm}$ ). The elution was performed with $150 \mathrm{ml}$ pentane $\mathrm{CH}_{2} \mathrm{Cl}_{2}$ (2:1), $150 \mathrm{ml}$ pentane/ether $(9: 1)$ and $150 \mathrm{ml}$ pentane/ether $(5: 1) .20 \mathrm{ml}$ fractions were collected and analyzed by gas chromatography.

EI-MS (Ethyl $\left[2,2-{ }^{2} \mathrm{H}_{2}\right]-(E)-3,4$-epoxydecanoate): $m / z 216\left(\mathrm{M}^{+}\right.$, rel. int. $\left.0.02 \%\right), 55(100), 41$ (62), 103 (48), 43 (46), 56 (42), 69 (33), 57 (32), 73 (31), 75 (27), 45 (25); IK (DB WAX $60 \mathrm{~W}$ ): 1958.

${ }^{1} \mathrm{H}$ NMR $\left(270 \mathrm{MHz}, \mathrm{CDCl}_{3}\right): 2.76 \mathrm{ppm}(1 \mathrm{H}, \mathrm{dt}$, $\left.J_{\mathrm{H} 3-\mathrm{H} 4}=2.4 \mathrm{~Hz} ; J_{\mathrm{H} 4-\mathrm{H} 5}=5.4 \mathrm{~Hz}\right) ; 3.03 \mathrm{ppm}(1 \mathrm{H}$, $\mathrm{m}(\mathrm{br})$.$) .$

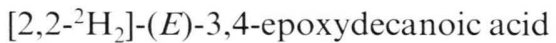

The ester bound was hydrolyzed with commercially available pig liver esterase. $100 \mathrm{mg}$ ethyl $\left[2,2-{ }^{2} \mathrm{H}_{2}\right]-3,4$-epoxydecanoate were disperged in $15 \mathrm{ml}$ phosphate buffer $\mathrm{pH}$ 7.0. After addition of $50 \mu \mathrm{l}$ esterase solution $(=0.5 \mathrm{mg}$ protein $)$ the reaction mixture was shaken for $6 \mathrm{~h}$ at $25^{\circ} \mathrm{C}$ leading to a quantitative hydrolysis; the yielded acid was extracted with $100 \mathrm{ml}$ diethylether.

\section{Ethyl (E)-3,4-epoxydecanoate}

(E)-3-decenoate was esterified and epoxidized as described.

EI-MS (Ethyl (E)-3-decenoate): $m / z 198\left(\mathrm{M}^{+}\right.$, rel. int. 2\%), 55 (100), 41 (95), 69 (82), 43 (63), 54 (48), 110 (45), 88 (42), 83 (33), 39 (32).

EI-MS (Ethyl (E)-3,4-epoxydecanoate): $m / z 185$ ((M-29), rel. int. 0.1\%), 55 (100), 41 (98), 43 (97), 101 (75), 71 (58), 57 (54), 56 (52), 42 (45), 69 (44), 73 (39).

${ }^{1} \mathrm{H}$ NMR $\left(270 \mathrm{MHz}, \mathrm{CDCl}_{3}\right): 2.54 \mathrm{ppm}(2 \mathrm{H}$, $\left.\mathrm{dd}, J_{\mathrm{H} 2-\mathrm{H} 2^{\prime}}=16.2 \mathrm{~Hz} ; J_{\mathrm{H} 2-\mathrm{H} 3}=5.7 \mathrm{~Hz}\right) ; 2.75 \mathrm{ppm}$ $\left(1 \mathrm{H}, \mathrm{dt}, J_{\mathrm{H} 4-\mathrm{H} 3}=2.4 \mathrm{~Hz} ; J_{\mathrm{H} 4-\mathrm{H} 5}=5.4 \mathrm{~Hz}\right)$; $3.04 \mathrm{ppm}\left(1 \mathrm{H}, \mathrm{dt}, J_{\mathrm{H} 3-\mathrm{H} 2}=5.7 \mathrm{~Hz} ; J_{\mathrm{H} 3-\mathrm{H} 4}=\right.$ $2.4 \mathrm{~Hz})$.

\section{Ethyl $\left[5,6-{ }^{2} \mathrm{H}_{2}\right]-(Z)-3,4$-epoxydecanoate}

$1 \mathrm{ml}(E)$-2-heptenal was hydrogenated with Pd, $5 \%$ on charcoal and $\mathrm{D}_{2}$ in a gastight reaction vessel at 10 bar. Purification by fractionated distillation and by LSC on silica gel yielded in $720 \mu \mathrm{l}$ $\left[2,3-{ }^{2} \mathrm{H}_{2}\right]$-heptanal.

EI-MS ([2,3- $\left.{ }^{2} \mathrm{H}_{2}\right]$-heptanal): $m / z 116\left(\mathrm{M}^{+}\right.$, rel. int. $0.5 \%), 45$ (100), 43 (55), 42 (54), 44 (53), 71 (52), 72 (42), 46 (42), 41 (41), 56 (32), 83 (10); IK (DB WAX $60 \mathrm{~W}$ ): 1135 . 
According to the method described [21], $1.626 \mathrm{~g}$ triphenylphosphine and the aldehyde were combined and heated at $125^{\circ} \mathrm{C}$. $650 \mu \mathrm{l}$ ethyl acrylate were added to this clear solution and refluxed for $24 \mathrm{~h}$. The reaction product, ethyl $\left[5,6-{ }^{2} \mathrm{H}_{2}\right]-$ 3 -decenoate (yield $30 \%$, ratio $(Z):(E)=88: 12$ ), was purified by silica gel LSC. The resolution of the $(Z) /(E)$ isomers was achieved by LSC on silica gel, impregnated with $\mathrm{Ag}\left(\mathrm{NO}_{3}\right)$ [22].

EI-MS (Ethyl [5,6- $\left.{ }^{2} \mathrm{H}_{2}\right]-(Z)-3$-decenoate): $\mathrm{m} / \mathrm{z}$ $200\left(\mathrm{M}^{+}\right.$, rel. int. $\left.0.2 \%\right), 55(100), 41$ (99), 70 (86), 56 (74), 42 (72), 88 (57), 111 (51), 153 (17), 154 (8); IK (DB WAX $60 \mathrm{~W})$ : 1641.

Epoxidation and purification of the epoxide were performed as described for the $(E)$-isomer.

EI-MS (Ethyl [5,6- $\left.{ }^{2} \mathrm{H}_{2}\right]-(Z)-3,4$-epoxydecanoate): $m / z 171$ (M-45, rel. int. $0.2 \%), 56(100), 55$ (93), 43 (84), 101 (73), 71 (73), 42 (72), 41 (67), 57 (63), 44 (47), 70 (45); IK (DB WAX 60 W): 1980.

${ }^{1} \mathrm{H}$ NMR $\left(270 \mathrm{MHz}, \mathrm{CDCl}_{3}\right): 2.55 \mathrm{ppm}(2 \mathrm{H}$, $\left.\mathrm{dd}, J_{\mathrm{H} 2-\mathrm{H} 2^{\prime}}=14 \mathrm{~Hz} ; J_{\mathrm{H} 2-\mathrm{H} 3 / \mathrm{H} 2^{\prime}-\mathrm{H} 3}=6.3 \mathrm{~Hz}\right)$; $2.97 \mathrm{ppm}\left(1 \mathrm{H}, \mathrm{dt}, J_{\mathrm{H} 4-\mathrm{H} 3}=2.5 \mathrm{~Hz}, J_{\mathrm{H} 4-\mathrm{H} 5}=\right.$ $6.3 \mathrm{~Hz}) ; 3.30 \mathrm{ppm}\left(1 \mathrm{H}, \mathrm{dt}, J_{\mathrm{H} 3-\mathrm{H} 4}=2.5 \mathrm{~Hz}, J_{\mathrm{H} 3-}\right.$ $\mathrm{H} 2=6.3 \mathrm{~Hz}$ ).

\section{Feeding experiments}

S. odorus ATCC 24259 was grown aerobically (air flow rate: $1 \mathrm{vvm}$ ) at $24{ }^{\circ} \mathrm{C}$ in a 101 - fermenter. The medium contained (in 11 of deionized water): $45 \mathrm{~g}$ sucrose, $5 \mathrm{~g}$ lactose, $3.0 \mathrm{~g} \mathrm{MgSO}_{4} \cdot 7 \mathrm{H}_{2} \mathrm{O}$, $2.5 \mathrm{~g}\left(\mathrm{NH}_{4}\right)_{2} \mathrm{SO}_{4}, 2.5 \mathrm{~g} \mathrm{KH}_{2} \mathrm{PO}_{4}, 2.5 \mathrm{~g}$ L-Alanin and $0.1 \mathrm{~g} \mathrm{CaCl} \cdot 2 \mathrm{H}_{2} \mathrm{O}$. After $77 \mathrm{~h} 11$ culture broth $(=3 \mathrm{~g}$ cell dry weight) was centrifuged for each incubation experiment and the cells were washed twice with $\mathrm{m} / 15$ phosphate buffer, $\mathrm{pH} 6.8$. Cells were resuspended in $30 \mathrm{ml}$ phosphate buffer and filled in $100 \mathrm{ml}$ Erlenmeyer flasks, containing $10 \mathrm{mg}$ of the incubation substrate. The flasks were shaken at $26^{\circ} \mathrm{C}$ for $4 \mathrm{~h}$ and the reaction was stopped by adding $50 \mathrm{ml}$ diethylether with subsequent extraction of volatiles.

\section{Analysis of volatiles}

The incubation broth was extracted with $2 \times 50 \mathrm{ml}$ diethylether and the acids were methylated with diazomethane. After concentration to $0.2 \mathrm{ml}$, the extract was transformed to a LSC column ( $4.5 \mathrm{~g}$ silica gel) and separated into four $40 \mathrm{ml}$-fractions: (Fraction I: pentane $/ \mathrm{CH}_{2} \mathrm{Cl}_{2}$
(9:1); fraction II: pentane $/ \mathrm{CH}_{2} \mathrm{Cl}_{2}$ (2:1); fraction III: pentane/ether $(9: 1)$; fraction IV: ether).

Gas chromatographic analysis was performed on a Carlo Erba 4100 gas chromatograph, equipped with a DB Wax $60 \mathrm{~W}(60 \mathrm{~m} / 0.32 \mathrm{~mm}$ internal diameter, J\&W).

\section{Determination of optical purity}

$\gamma$-Decalactone was isolated by preparative gas chromatography. As described elsewhere [23], the lactone was transformed with butylamine into the corresponding 4-hydroxydecanamide. The conversion into the diastereomeric 4-[( $R)-[(1-$ phenylethyl)carbamoyl]oxy]N-butyldecanamide was achieved by reaction with $(R)-(+)-1$-phenylethylisocyanate.

\section{Mass spectrometry}

GC-MS investigations were carried out using a Finnigan (quadrupole) mass spectrometer, model 4510 , combined to a Finnigan 9610 gas chromatograph, equipped with a DB Wax $60 \mathrm{~W}$. The diastereomeric 4-[( $R)-[(1$-phenylethyl)carbamoyl $]$ oxy $]-$ $\mathrm{N}$-butyldecanamides were separated on a DB 210 capillary column $(30 \mathrm{~m} / 0.32 \mathrm{~mm}$ internal diameter, J \& W).

For electron impact ionization (EI-MS) the ionization potential was $70 \mathrm{eV}$ and the scan range was $35-350 \mathrm{Da} / 0.8 \mathrm{~s}$. For chemical ionization (CIMS) methane was used as the CI reagent gas at a pressure of 0.5 torr. The source temperature was maintained at $200{ }^{\circ} \mathrm{C}$. The scan range was $80-350 \mathrm{Da} / 0.8 \mathrm{sec}$. Scanning and data processing were accomplished with an INCOS data system.

\section{${ }^{l} H$ NMR Spectroscopy}

${ }^{1} \mathrm{H}$ NMR spectra were recorded at $270 \mathrm{MHz}$ on a Bruker WH $270 \mathrm{NMR}$ spectrometer in $\mathrm{CDCl}_{3}$ solutions. Chemical shifts are referenced to tetramethylsilane $\left(\left(\mathrm{CH}_{3}\right)_{4} \mathrm{Si}\right)$ as internal standard.

\section{Results}

\section{Incubation substrates}

Fig. 1 presents the spectral data of ethyl $\left[2,2-{ }^{2} \mathrm{H}_{2}\right]-(E)-3,4$-epoxydecanoate and the corresponding non labeled compound. The characteristic fragmentation pattern of the CI spectra makes 

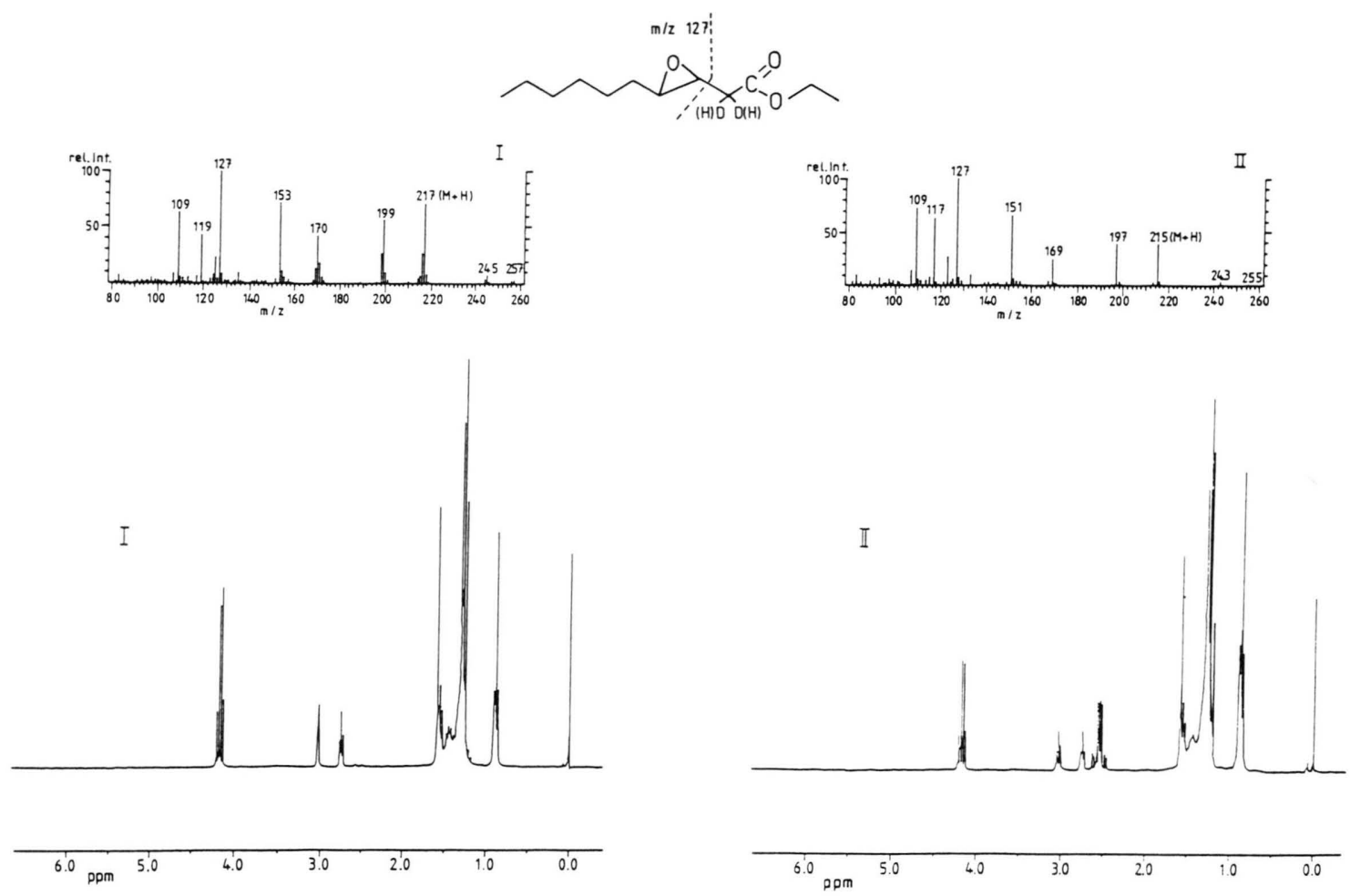

Fig. 1. CI-MS and 'H NMR spectra of ethyl $\left[2,2-{ }^{2} \mathrm{H}_{2}\right]-(E)-3,4$-epoxydecanoate $(\mathrm{I})$ and ethyl $(E)$-3,4-epoxydecanoate (II).

it possible to localize the position of the isotopes. The base peak $(m / z 127)$ in both compounds refers to the cleavage between $\mathrm{C}_{2}$ and $\mathrm{C}_{3}$. In conclusion, the deuterium atoms are fixed to $\mathrm{C}_{2}$. The ${ }^{1} \mathrm{H}$ NMR spectra are in accordance with the mass spectra. Compared to the unlabeled reference, the resonance signal for the $\alpha$-methylene protons disappeared and the double triplett for the proton at $\mathrm{C}_{3}$ shifted to a broad multiplett, due to the coupling of ${ }^{1} \mathrm{H}-{ }^{2} \mathrm{H}$.

The chemical stability of the substrates was tested under incubation conditions. After extraction and chromatography on silica gel neither a hydrolytic cleavage of the oxirane ring nor a loss of deuterium could be observed.

The mass spectrum of ethyl $\left[5,6-{ }^{2} \mathrm{H}_{2}\right]-(Z)-3,4-$ epoxydecanoate reveals that the substrate was not uniformly deuterated in position $\mathrm{C}_{5}$ and $\mathrm{C}_{6}$ (Fig. 2). Both, the $[\mathrm{M}+\mathrm{H}]^{+}$-peak $(m / z$ 216/217) and the fragment ions $m / z 128$ and 129 , resulting from the $\alpha$-cleavage indicate that the compound

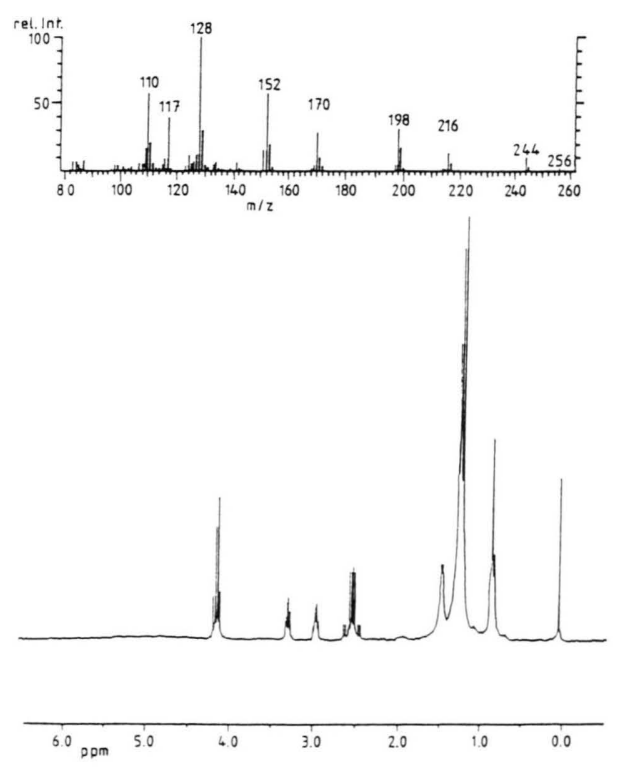

Fig. 2. CI-MS and ${ }^{1} \mathrm{H}$ NMR spectra of ethyl $\left[5,6-{ }^{2} \mathrm{H}_{2}\right]-$ (Z)-3,4-epoxydecanoate. 

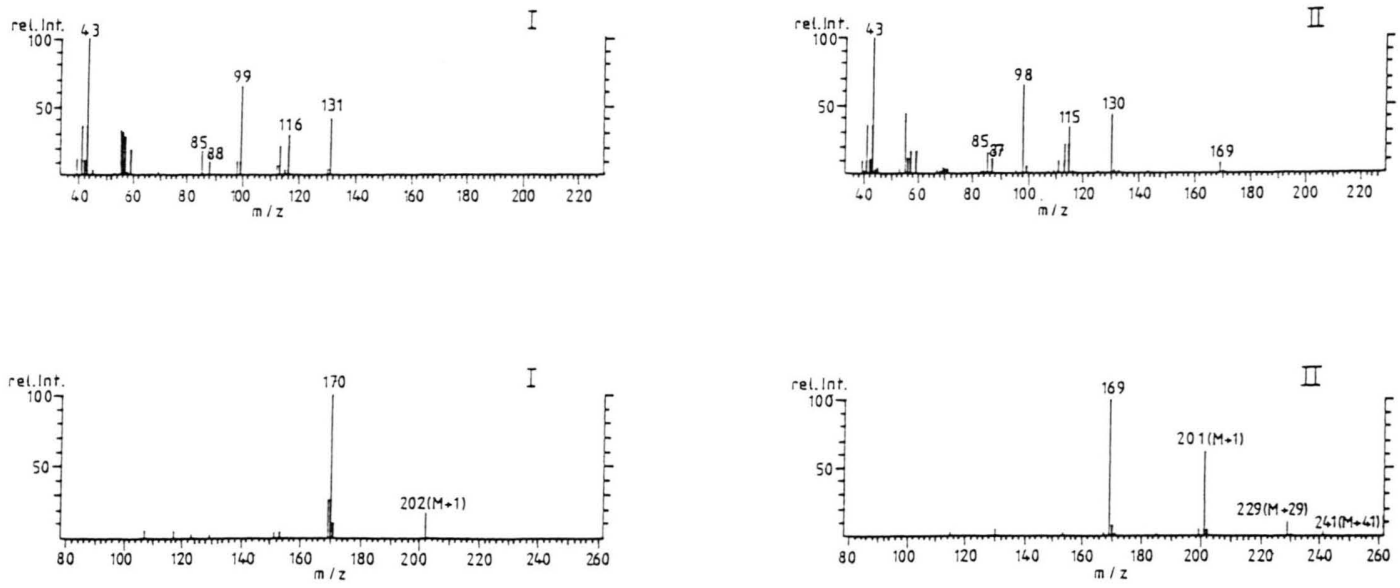

Fig. 3. EI- und CI-MS of methyl 4-oxodecanoate: (I) detected in fraction III of the ether extract after incubation of ethyl $\left[2,2-{ }^{2} \mathrm{H}_{2}\right]-(E)-3,4-$ epoxydecanoate and (II) authentic reference.

was a mixture of single and double deuterated epoxy ester.

\section{Feeding experiments}

Different incubation experiments revealed that added precursors were optimally metabolized by cells harvested after a fermentation period of 60 to $80 \mathrm{~h}$. Additionally, the low concentrations of naturally formed fatty acids and lactones makes it possible to detect the labeled products even at low metabolization rates of the added incubation substrates.

Incubation of ethyl (E)-3,4-epoxydecanoate and (E)-3,4-epoxydecanoic acid

A high esterase activity of the $S$. odorus cells resulted in a complete hydrolysis of the added ethyl ester within a incubation period of $4 \mathrm{~h}$. The metabolization rate of the hydrolytically formed epoxy acid was about $5 \%$, comparable to the result obtained after incubation of $(E)$-3,4-epoxydecanoic acid.

The metabolites subsequently described were detected after incubation either of the ester or of the acid.

The ether extract of the incubation broth was methylated and fractionated on silica gel before GC and GC/MS investigation. The non-metabolized substrate and methyl 4-oxodecanoate were collected in Fraction III. The deuterium labeling of methyl 4-oxodecanoate is evident by its mass spectral data (Fig. 3). In the EI mass spectrum, the fragment ions $m / z 116$ ( $\alpha$-cleavage), $m / z 131$ (McLafferty rearrangement) and $m / z 99(m / z 131$

- $\mathrm{CH}_{3} \mathrm{OH}$ ) contain the $\alpha$-methylene group and suggest the presence of only one deuterium. Additionally, molecular weight determination by CIMS $\left([\mathrm{M}+\mathrm{H}]^{+}: m / z\right.$ 202) points to the loss of one ${ }^{2} \mathrm{H}$-isotope in the course of generation of this compound. An enzymatic step should be responsible for the abstraction of one deuterium, because the chemical stability of the labeling has been verified.

The reconstructed ion chromatogram of the polar fraction IV of the ether extract is presented in Fig. 4. Peak a, b, and c correspond to the naturally

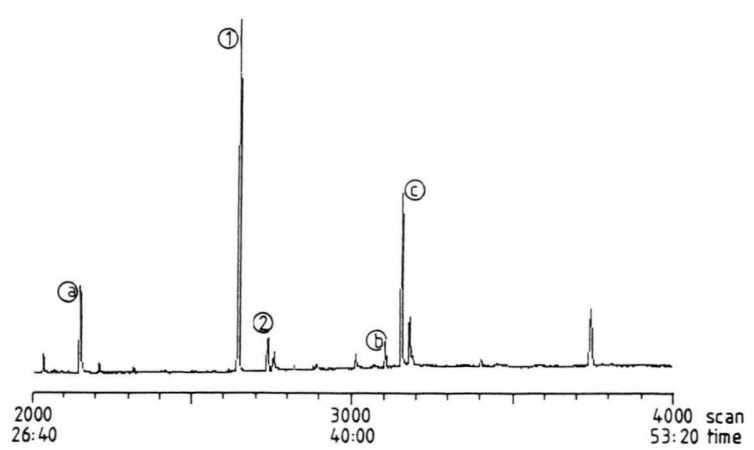

Fig. 4. Capillary gas chromatogram (reconstructed ion detection) of the polar fraction after incubation of ethyl $\left[2,2-{ }^{2} \mathrm{H}_{2}\right]-(E)-3,4$-epoxydecanoate to cells of $S$. odorus (DB WAX $60 \mathrm{~W} 60 \mathrm{~m} \times 0.32 \mathrm{~mm}$ i.d., temperature programmed from $70{ }^{\circ} \mathrm{C}$ (3 min isothermal) to $220^{\circ} \mathrm{C}$ at $4 \mathrm{C} / \mathrm{min})$. 

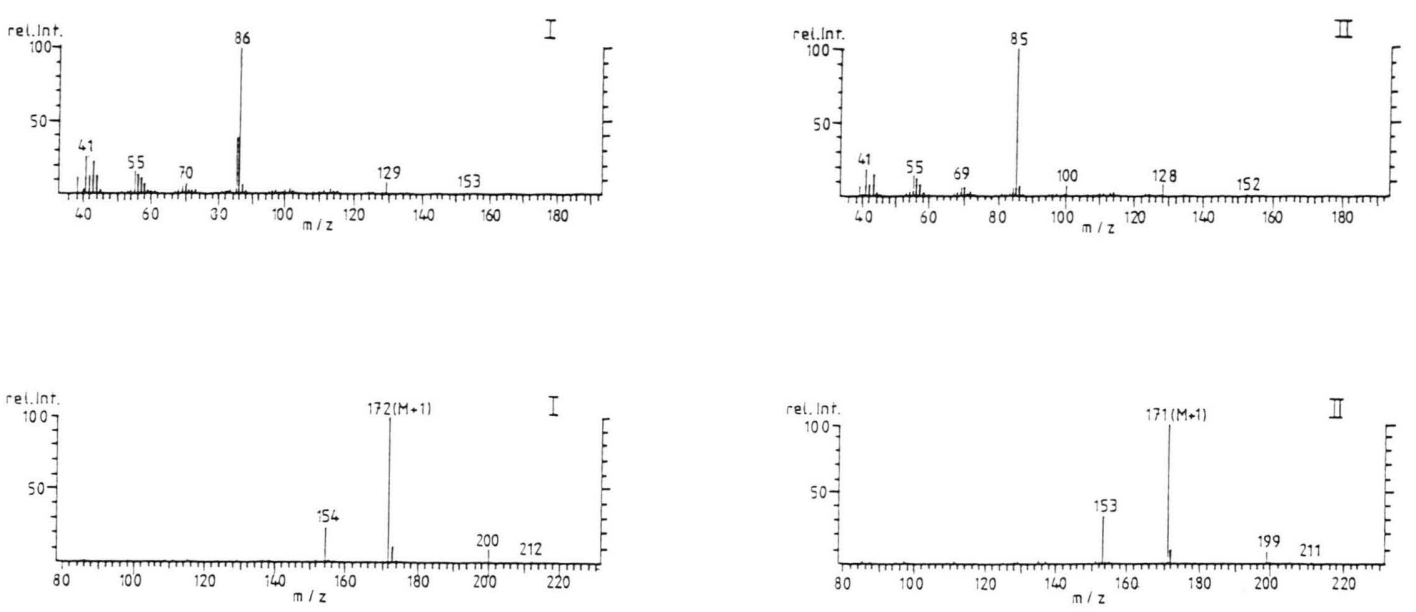

Fig. 5. EI- and CI-MS of $\gamma$-decalactone: (I) corresponding to peak 1 in Fig. 4; (II) authentic reference.

formed, unlabeled metabolites 2-phenylethanol (a), $\gamma$-dodecalactone (b), and (Z)-6-dodecen4-olide (c), respectively.

Fig. 5 shows the mass spectrum of $\gamma$-decalactone (Peak 1 in Fig. 4). The base peak at $m / z 86$ instead of $m / z 85$ and the molecular weight determination $\left([\mathrm{M}+\mathrm{H}]^{+}: m / z 172\right.$ instead of $\left.m / z=171\right)$ characterize the difference of the labeled and unlabeled compound.

The enantiomeric composition of the formed $\gamma$-decalactone, isolated by preparative GC, was investigated by capillary GC after derivatization into the corresponding diastereomeric $4-[(R)-[(1-$ phenylethyl)carbamoyl]oxy]N-butyldecanamides [23]. The chromatograms of the separated diastereoisomers, presented in Fig. 6, correspond to the racemic reference (I), the naturally biosynthesized lactone (II), and to the product, isolated from the incubation experiment (III). The enantiomeric ratio of the lactone, isolated after the biotransformation of the epoxide, was $(S):(R)=(31: 69) \%$, compared to the biosynthesized optically pure $(R)-(+)-\gamma$-decalactone; this indicates a non-enantioselective metabolism of the added racemic precursor. Additional experiments revealed that the enantiomeric ratio is not constant but depends on (a) the transformation rate of the added precursor and (b) on the amount of previously biosynthesized lactone in the course of growth.

The mass spectral investigation of the separated diastereoisomers gives evidence for the assumption of an unspecific metabolism (Fig. 7). The mass spectra of 4-[(R)-[(1-phenylethyl)carbamoyl]oxy]N-butyldecanamides are characterized by the fragment ion M-164, according to the abstraction of phenylethylcarbamate. Therefore, the fragment $m / z 227$ of the derivative of the (S)-enantiomer reveals the deuterium labeling. The derivative of the
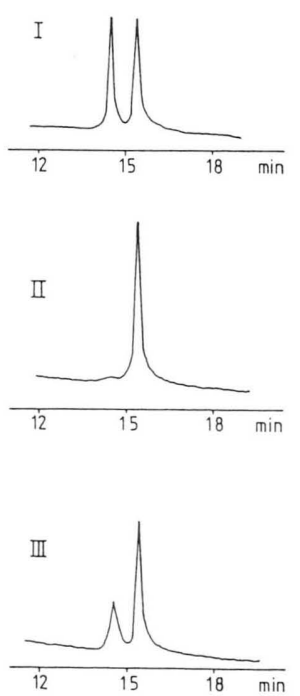

Fig. 6. Capillary GC-separations of $(S)$ - and $(R)$ 4-[(R)-[(1-phenylethyl)carbamoyl] oxy]N-butyldecanamide (DB $21030 \mathrm{~m} \times 0.32 \mathrm{~mm}$ i.d.; temperature programmed from $220^{\circ} \mathrm{C}$ (5 min isothermal) to $260{ }^{\circ} \mathrm{C}$ at $1 \mathrm{C} / \mathrm{min}$ ): (I) derivatives of racemic $\gamma$-decalactone; (II) derivatives of biosynthesized lactone of Sp. odorus; (III) derivatives of $\gamma$-decalactone, isolated after incubation of ethyl $\left[2,2-{ }^{2} \mathrm{H}_{2}\right]-(E)-3,4$-epoxydecanoate. 

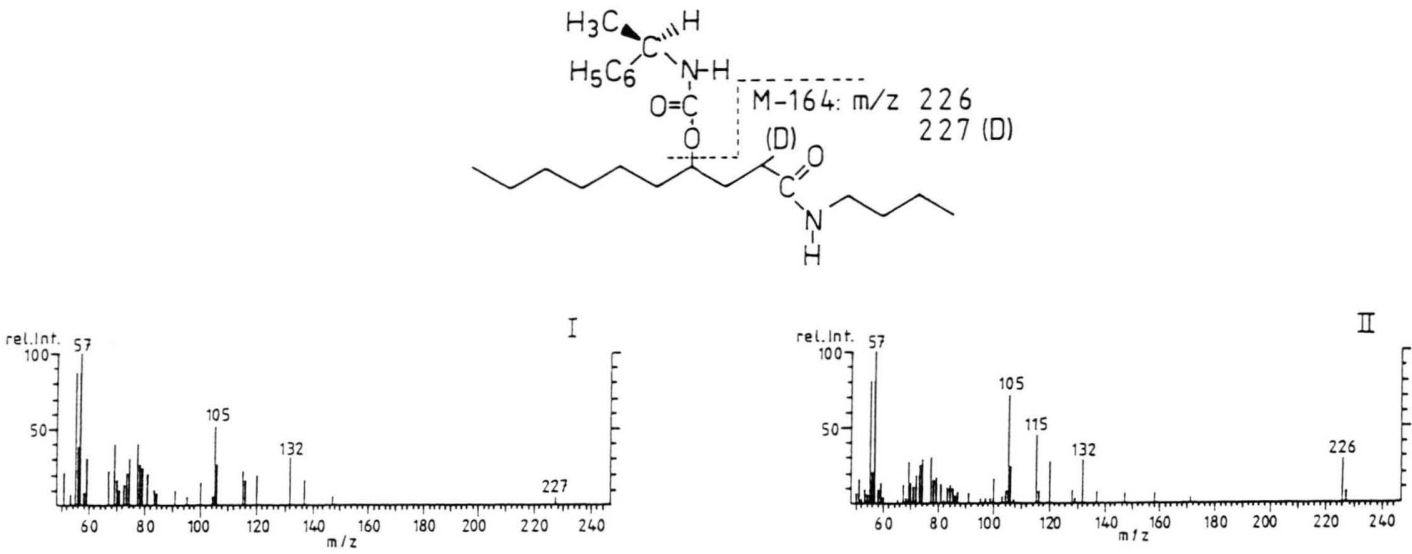

Fig. 7. EI-MS of the separated diastereomeric derivatives of $\gamma$-decalactone, isolated from the polar fraction of the extract after incubation of ethyl (E)-3,4-epoxydecanoate: (I) corresponding to $(S)$ - $\gamma$-decalactone; (II) corresponding to $(R)-\gamma$-decalactone.

(R)-enantiomer, with $\mathrm{m} / \mathrm{z} 226$ and $\mathrm{m} / \mathrm{z} 227$ is a mixture of the naturally formed and the precursor derived lactone.

Peak 2 in the reconstructed ion chromatogram corresponds to 2-decen-4-olide, which was identified by comparison to gas chromatographic and mass spectrometric data of the synthesized unlabeled reference compound (Fig. 8). The fragment ion $m / z 85$ in the labeled metabolite, in contrast to $m / z 84$ of the authentic reference, is due to the abstraction of the alkyl moiety after hydrogen rearrangement [24]. After administration of unlabeled ethyl (E)-3,4-epoxydecanoate, the mass spectra of 2-decen-4-olide obtained from the incubation experiment were identical to the reference.

Incubation of ethyl $\left[5,6-{ }^{2} \mathrm{H}_{2}\right]-(\mathrm{Z})-3,4-$ epoxydecanoate

In contrast to the described biotransformation of the $(E)$-isomer, after incubation of ethyl $\left[5,6-{ }^{2} \mathrm{H}_{2}\right]-(Z)-3$-decenoate none of the described metabolites were detected. The EI- and CI mass spectra of $\gamma$-decalactone, which has been the main constituent of the biotransformation of the $(E)$ isomer, correspond exactly to the reference com-
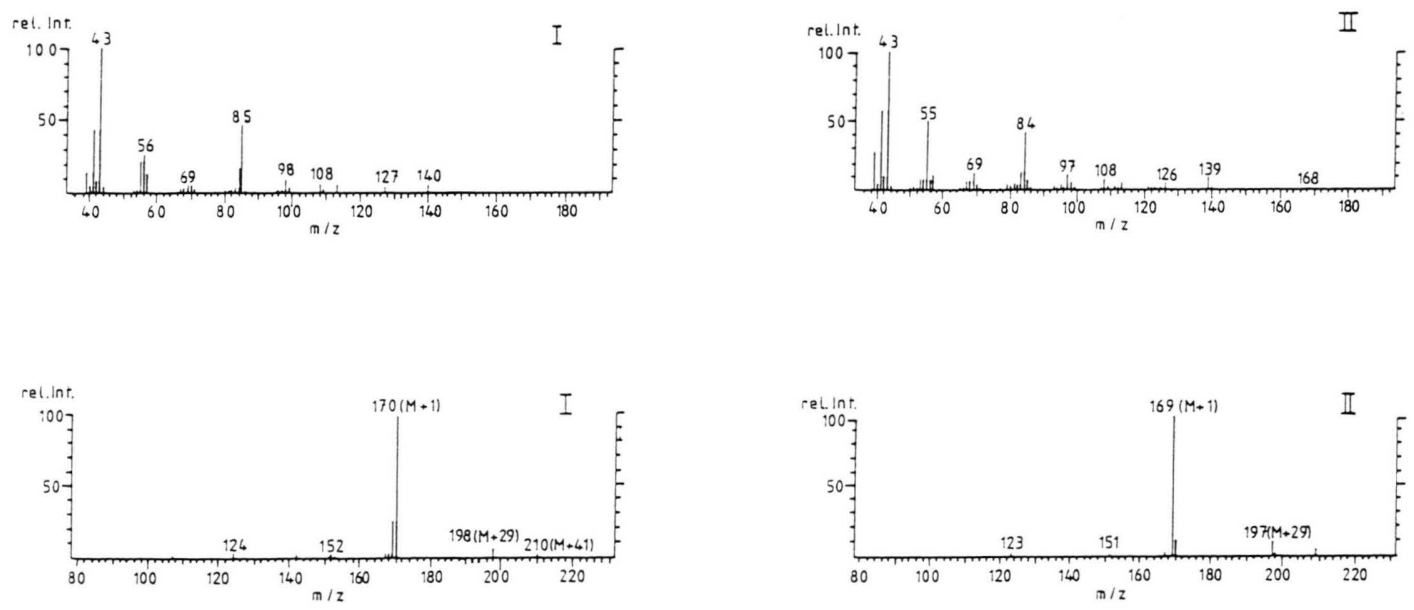

Fig. 8. EI- and CI-MS of 2-decen-4-olide: (I) corresponding to peak 2 in Fig. 4; (II) authentic reference. 
pound. Apart from the hydrolysis of the ethyl ester, no additional reaction could be detected.

\section{Discussion}

Scheme 1 summarizes the proposed enzymatic steps leading to the identified products after incubation of ethyl $\left[2,2-{ }^{2} \mathrm{H}_{2}\right]-(E)-3,4$-epoxydecanoate or the corresponding acid. Generally, epoxides are metabolized by hydration, catalyzed by epoxide hydrolases (EC 3.3.2.3.) or glutathione S-transferases (EC 2.5.1.18.). In plant and microbial systems, only the hydrolases have been characterized. According to their physiological function as detoxifying enzymes, hydrolases from microsomes of animal tissue catalyze the hydration of a broad spectrum of substrates $[25,26]$. In contrast to that, but corresponding to the specificity of the hydrolysis of the epoxy group observed in this study, the substrate specificity of an epoxide hydrolase, responsible for the biosynthesis of trihydroxystearate in the skin of young apples is very high [27].

The first intermediate in the metabolism of the epoxide, 3,4-dihydroxydecanoic acid, could not be detected. We assume that after intracellular hydration, the polar dihydroxyacid can not pass the membranes. Alternatively, it might be possible that the intermediate dihydroxyacid is rapidly oxidized with high enzymatic activity. Studies on the formation of lactones from long chain fatty acids using biotransformations of hydroxylated substrates, e.g. ricinoleic acid and erythro-9,10-dihydroxystearic acid, resulted also in an oxidation to the corresponding oxo or ketohydroxy compounds, respectively [20]. Analoguously, the postulated intermediate might be oxidized to 3-oxo4-hydroxydecanoic acid, which is chemically instable.

The accumulation of 2-decen-4-olide can be interpreted by two enzymatic steps with subsequent chemical or enzymatically catalyzed lactonization. After transformation of the dihydroxyacid into its CoA derivative, the formation of 4-hydroxy2-decenoyl-CoA can be explained by a reverse reaction of an enoyl-CoA hydratase. Recently, Smeland et al. described the activities of two enoyl hydratases with opposite enantioselectivities, responsible for the epimerization of $(R)$ 3-hydroxyoctanoyl-CoA [28]. An unspecific hydration of the racemic epoxy ester is leading to a dihydroxy acid with both $(R)$ - and $(S)$-3-hydroxy groups. According to the described mechanism [28], the $(R)$-3-hydroxy group can be dehydrated to 4-hydroxy-(E)-2-decenoyl-CoA or into 4-hydroxy-(Z)-2-decenoyl-CoA. Because the formation of 2-decen-4-olide requires the $(Z)$-configuration of the double bond, the reverse reaction of the $(Z)$-2-enoyl hydratase should be active. The detection of this unsaturated lactone, which is not

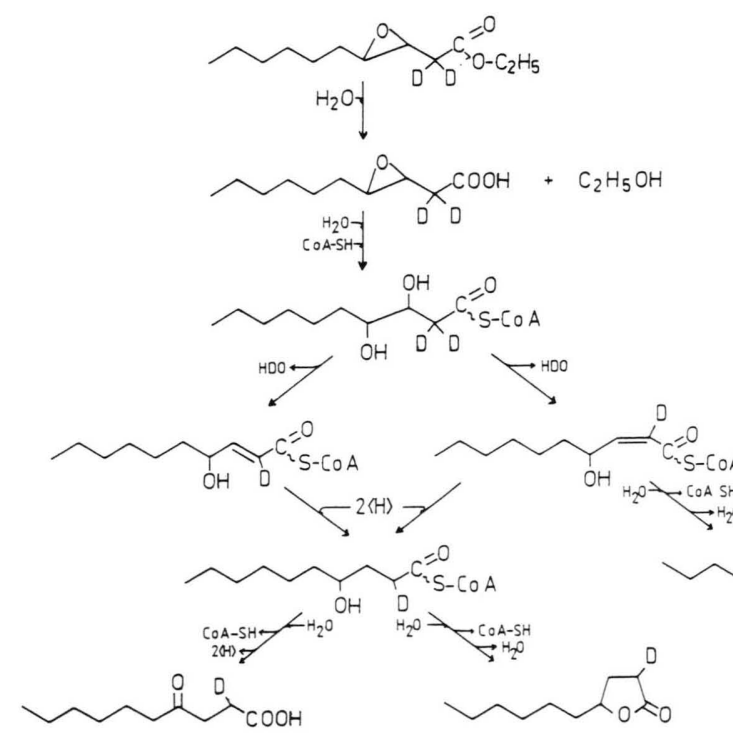
epoxydecanoate by cells of $S$. odorus. 
naturally formed by $S$. odorus indicate that the epoxidation of (E)-3-decenoic acid or its CoA-ester proceeds enantioselectively. Additionally, this reaction explains the loss of one deuterium in all labeled metabolites.

After enzymatic hydrogenation, the resulting 4-hydroxydecanoic acid, which could be detected as a trace constituent, either cyclisizes to the final metabolite, $\gamma$-decalactone, or is oxidized to 4-oxodecanoic acid.

The formation of 2-alken-4-olides and the corresponding saturated lactones with chain length from $\mathrm{C}_{6}$ to $\mathrm{C}_{10}$ by the basidiomycete Polyporus durus [29] can be also explained with the proposed pathway.

After incubation of ( $Z$ )-3,4-epoxydecanoic acid, no metabolites could be detected. Therefore, we assume that the $(E)$-isomer is the genuine precursor leading to $\gamma$-decalactone. (E)-3-decenoyl-CoA is formed during $\beta$-oxidation of linoleic acid after hydrogenation of $(E, Z)$-2,4-decadienoyl-CoA $[17,18]$. The first step in the biosynthesis of $\gamma$-decalactone in $S$. odorus should be the epoxidation of the double bond of this intermediate. The fact, however, that this initial step could not be demonstrated after administration of deuterated (E)-3-decenoic acid, can be explained by the sensitivity of the enzymes involved in the epoxidation. Duppel et al. demonstrated that yeast microsomal hydroxylation systems are sensitive towards higher concentrations of substrates [30]. Because of the high optical purity of the naturally occurring $\gamma$-decalactone and the non-enantioselective transformation of $(E)$-3,4-epoxydecanoate, it can be concluded that the biogeneration is initiated by an enantioselective epoxidation.

In contrast to $\gamma$-decalactone, other $\gamma$-lactones which are accumulating in the fermentation broths of this yeast, $\gamma$-hexa-, $\gamma$-nona, and ( $Z$ )-6-dodecen4-olide are not optically pure but occur in constant enantiomeric ratios [20]. The minor enantioselectivity during formation of these compounds may be referred to the activity of other enzymes, which exhibit different selectivities, or a common enzymatic system, responsible for the formation of all lactones, characterized by a substrate dependent enantioselectivity.

For a more detailed investigation of this enzymatic system, it is necessary to reproduce the described metabolic steps in a cell-free extract of this organism. But, until now, the disintegration of the yeast cells resulted in a complete loss of the capacity to metabolize added epoxides.

\section{Acknowledgement}

We wish to thank J. Heidlas for helpful discussions and commenting on the manuscript. 
[1] J. A. Maga, CRC Crit. Rev. Sci. Nutr. 1976, 1.

[2] N. Hayashi, H. Kawaguchi, A. Nishi, and $\mathrm{H}$. Komae, Z. Naturforsch. 42 c, 1001 (1987).

[3] R. G. Yarger, R. M. Silverstein, and W. E. Burkholder, J. Chem. Ecol. 1, 323 (1975).

[4] R. Näf-Müller and B. Wilhalm, Helv. Chim. Acta 54, 1880 (1971).

[5] K.-H. Engel, J. Heidlas, W. Albrecht, and R. Tressl, in: Flavor Chemistry: Trends and Developments (R. Teranishi, R. G. Buttery, and F. Shahidi, eds.), ACS Symp. Series 388, pp. 8-22 (1989).

[6] J. Heidlas, Ph.D. thesis, TU Berlin, in prep.

[7] J. Boldingh and R. J. Taylor, Nature 194, 909 (1962).

[8] J. L. Weihrauch, C. D. Brewington, and D. P. Schwartz, Lipids 9, 883 (1974).

[9] T. G. Muys, B. van der Ven, and A. P. de Jonge, Nature 194, 995 (1962).

[10] P. S. Dimick, N. J. Walker, and S. Patton, Biochem. J. 111, 395 (1969).

[11] N. J. Walker, S. Pattom, and P. S. Dimick, Biochem. Biophys. Acta 152, 445 (1968).

[12] R. Tressl, M. Apez, R. Arrieta, and K. G. Grünewald, in: Flavors of Foods and Beverages (G. Charalambous and G. E. Inglett, eds.), pp. 145168, Acad. Press, London, New York 1978.

[13] G. Urbach, Lebensmittel-Wiss. u. Technol. 15, 62 (1982).

[14] R. Tressl, J. Heidlas, W. Albrecht, and K.-H. Engel, in: Bioflavor '87 (P. Schreier, ed.), pp. 221-236, W. de Gruyter, Berlin, New York 1988.

[15] W. Stoffel, R. Ditzner, and H. Caesar, HoppeSeyler's Z. Physiol. Chem. 339, 167 (1964).
[16] D. Cuebas and H. Schulz, J. Biol. Chem. 257, 14140 (1982).

[17] W.-H. Kunau and P. Dommes, Eur. J. Biochem. 91, 553 (1978).

[18] P. Dommes, V. Dommes, and W.-H. Kunau, J. Biol. Chem. 258, 10846 (1983).

[19] Cytochrome P-450 (K. Ruckpaul and H. Rein. eds.), Akademie-Verlag, Berlin 1984.

[20] Unpublished results.

[21] H. J. Bestmann, K. H. Koschatzky, W. Schätzke, J. Süß, and O. Vostrowsky, Liebigs Ann. Chem. 1981, 1705.

[22] T. Norin and L. Westfeld, Acta Chem. Scand. 17, 1828 (1963).

[23] K.-H. Engel, W. Albrecht, and J. Heidlas, J. Agric. Food Chem., in press.

[24] W. A. May, R. J. Peterson, and S. S. Chang, J. Food Sci. 43, 1248 (1978).

[25] F. Oesch, N. Kaubisch, D. M. Jerina, and J. W. Daly, Biochemistry 10, 4858 (1971).

[26] A. Y. H. Lu, D. Ryan, D. M. Jerina, J. W. Daly, and W. Lewin, J. Biol. Chem. 250, 8283 (1975).

[27] R. Croteau and P. E. Kolattukudy, Arch. Biochem. Biophys. 170, 73 (1975).

[28] T. E. Smeland, J. Li, Ch. Chu, D. Cuebas, and H. Schulz, Biochem. Biophys. Res. Commun. 160, 988 (1989).

[29] R. G. Berger, K. Neuhäuser, and F. Drawert, Z. Naturforsch. 41 c, 963 (1986).

[30] W. Duppel, J.-M. Lebeault, and M. J. Coon, Eur. J. Biochem. 36, 583 (1973). 